\title{
Effectiveness of a Philosophy Education Program on Development of Moral Judgment, Pro-social Behavior and Anger Control in Students
}

\author{
M. Faraji (Mahrokh Faraji)', B. Makvandi (Behnam Makvandi)2, S. B. Pour (Saeed \\ Bakhtiyar Pour)2, Zahra Eftekhar Saadi Z. E. Saadi (Zahra Eftekhar Saadi )², \\ P. Ehteshamzadeh (Parvin Ehteshamzadeh)²
}

${ }^{1}$ Ph.D. student, Department of Psychology, Ahwaz Branch, Islamic Azad University, Ahwaz, IR

2 Assistant Professor, Department of Psychology, Ahwaz Branch, Islamic Azad University, Ahwaz, IR

\section{E-mail address:}

makvandi_b@yahoo.com

\section{Reprint address:}

Behman Makvandi

Golestan Highway

Farhang Shahr

Ahwaz, IR

Source: Clinical Social Work and Health Intervention

Pages: $44-55$
Volume: 9

Issue: 3

\section{Reviewers:}

Lesley Bucko - misia@vssvalzbety.sk

Pavel Czarnecki - pawel@czarnecki.co

\section{Key words:}

Philosophy Education. Moral Judgment. Pro-social Behavior. Anger Control. Second Year High School students.

\section{Publisher:}

International Society of Applied Preventive Medicine i-gap

CSWHI 2018; 9(3): 44 - 55; DOI 10.22359/cswhi_9_3_05 @ 2018 Clinical Social Work and Health Intervention

\section{Abstract:}

This research has been carried out with the aim of determining the effectiveness of a Philosophy Education Program on the development of moral judgment, pro-social behavior and anger control among students. 
This experimental field study was a pre-test and post-test type with control group and conducting follow up stages. The statistical population of the study consisted of all second year High School female students in Ahwaz City: 40 students were selected out of 160 students by using a multistage cluster random sampling method and were assigned in an experimental group (20 people) and a control group (20 people) through simple random sampling. The experimental group was exposed to the Philosophy Education Program for 2 months and the control group didn't receive any kind of intervention. The follow up stage was conducted after the post-test program and one and a half months after the intervention. Lotf Abadi's Ethical Development Questionnaires, Pro-social Behavior Questionnaire of Carole et al and Eysenck \& Wilson's Aggression Questionnaire were used to collect information. Data analysis was conducted using Multivariate Covariance Analysis (MANCOVA) and ANCOVA's single-variable analysis method. At the significant level of $p<0.001$, the research results showed that Philosophy Education affects the development of moral judgment, pro-social behavior and anger control among students and this result was persistent in the follow up phase.

\section{Introduction}

Today's human is facing a great treasure of human knowledge and business more than ever and the dominance of this treasure is growing every day. Despite the fact that access to this treasure of information has become readily possible through multiple sources, judgment, selecting and choosing relevant and appropriate information from the mass of information has become an extremely difficult task and requires high intellectual and mental skills (Maroofi \& Mohammadnia 2013).

During adolescence, the topic of ethics and ethical values and judgments are being more seriously discussed and as a social phenomenon, play an essential role in shaping, controlling and anticipating the actions and tendencies of people in society (Mahdavi \& Zarei 2011). Among the scholars in the field of ethical development, Lawrence Kelberg raised the main theory about adolescents' thoughts of right and wrong. Kelberg's Theory is important in understanding moral development in adolescence because it is a description of advanced concepts that individuals use in understanding social interactions, like stories that are tied to the concepts of society, regulation and relationships (Santrock 2014). If we engage the teenagers' mind with philosophical debates, we can grow their way of thinking. Lipman argues that Philosophy is an educational activity for children that improves their way of thinking and uses Philosophy as a method for fostering ethical and critical thinking and judgment (Lipman 2003).

The Training Program of philosophical thinking has clear cognitive objectives; persuades the mind to act; is doing it through challenges, principled thinking and structural interaction. The Philosophy Education Program is a successful method in teaching a way of thinking. The global experience and evidence in more than 50 countries shows that Philosophy for children has contributed to the development of thinking skills (Brahman \& Khodabakhshi 2017). In the process of searching for teaching Collective 
Philosophy, teenagers gradually become familiar with conversational skills and learn to listen to each other with politeness and respect; put their ideas together; adapt logical reasoning for unconfirmed ideas (Akrami et al., 2015). Ethical reasoning is directly related to the levels of ethical development in individuals. Reasoning and ethical judgment are known as the right and wrong decisions and beliefs that a person behaves consciously with these judgments. Ethical judgment is the reasoning or justifications that we take into account for ethical values or decisions (Uhlmann et al. 2015). In teaching Philosophy, Masi \& Santi's research (2015) showed that teaching Philosophy to children which is known as a fundamental component of free thinking education plays an important role in their moral judgments.

Jalilian et al. (2017) also indicates that teaching Philosophy to children has a positive effect on their problem solving ability and the development of ethical judgment among them. Students in the Philosophy teaching program become skilled and young explorers. Being an explorer is the main concept of this pattern; its purpose is to search actively; be a confident questioner and have a permanent consciousness for observing communications and differences; be ready all the time for comparison, coping, analysis and presenting hypothesis, experience, observation, assessment, and examination. Philosophy is a deep understanding and a kind of searching based on assessment for questions that people ask about their own lives and destinies; the beginning and end of the world; above all about immortality; understanding the fundamental cause of human desire to think, ponder and wisdom. The Philosophy of Learning isn't other people's points of view, but it is a kind of activity and an attempt to know (Brahman \& Khodabakhshi 2017).

Modifying the state of thinking s and putting the thinking element in the educational system in school is the initial aim of a Philosophy Program for children and adolescents and in the next stage, bringing up citizens who are sensible, self-critical, considerate and sensitive toward the social environment (Naji 2010 ). Social interaction during philosophical conversations paves the way for socialization along with proper judgment in children and adolescents, and increases the person's accountability in social life (Juuso 2007). In this regard, Ghobadian's research (2015) in the field of the effect of Philosophy teaching program on children and social skills of students indicates that the teaching program affected the social skills of fifth grade students and leads to an increase in interpersonal communication among Students.

Pro-social behavior is one of the variables influenced by Philosophy Teaching. Pro-social behavior focuses on factors such as the situation and also the person which makes it useful and helpful in situations where others are suffering (Atadokht et al. 2016). Iseng believes that community-friendly behaviors are purposeful actions that are carried out for the well-being of others (Gravand \& Manshai 2015). From Martin-Raugh et al.'s viewpoint (2016), the knowledge of pro-social behavior challenges human behavior in different situations and indirectly affects human behavior.

In a study that was carried out by $\underline{\text { Chadi }}$ et al. (2016) in the field of Philosophy Teaching for High School Students, research results showed that in addition to understanding reading in learning, the effect of participation in the philosophical searching circle increase's their community-friendly behaviors. Also, Leng's 2015 research on the role of teaching based on Philosophical Searching in High School Students showed that the process of students' philosophical questioning and sharing ideas and deep thinking makes stronger relations between students; increases their ability in making 
decisions; being the responsible member; committed to society. The results also indicate that in the philosophical searching process, having feelings of sympathy for others was promoted among students.

Adolescence is considered as one of the most important and outstanding stages of human's social and psychological growth and development which is associated with many stressful factors. This period represents a profound change that separates the child from the grownups causing many special issues that one of these main issues is anger and aggression which can be obviously seen in teenagers (Tajalinia \& Karimi 2014). Anger or aggression is a behavior aimed to hurt yourself or others. Anger may have destructive effects, including injury, damage, self-harm and harmful attacks to yourself or others followed by high-risk behaviors (Akbari \& Rahmati, 2015). Reducing emotional feelings and physiological excitement caused by anger; increasing the individual's knowledge about anger; teaching effective methods and strategies to control it is the purpose of anger control interventions through Philosophy Teaching (Taylaniya \& Karimi 2014).

In this regard, Hedayati (2011) conducted a research titled "Children Philosophy and Aggression Control" and the results of the study showed that Child Philosophy tries to provide the opportunity for reinforcing reasoning and judgment for children through creating a space named the searching circle. Also, the results indicate that aggression can be controlled through dialogue and strengthening logical and rational thinking in the child. The Philosophy Education Program creates the teaching of thinking alphabets in students. When students are placed in the searching circles, they will become self-confident, will love themselves and their social intelligence and interpersonal relationships will improve. Educational practitioners have contributed to children's thinking growth and their proper judgment from the very beginning of their childhood through considering Philosophy Teaching in the curriculum of schools in order to not get into trouble when they encounter various critiques and issues in their adulthood.

Based on the above mentioned, the current study was carried out with the aim of evaluating the effectiveness of Philosophy Training Program on development of moral judgment, pro-social behavior and anger control among second year High School female students of Ahwaz City.

\section{Method}

\section{Society and Sampling Method}

The statistical population of this study included all second year High School female students in Ahwaz City. This experimental field study was a pre-test and post-test type with control group and conducted follow up stages. In this research, a multistage cluster random sampling method was used for selecting the sample. Initially, 2 Districts were randomly selected from the quad areas of Ahwaz Education then a High School was randomly selected among the schools of Ahwaz, Education District 2: 20 students were randomly selected from each of the 8 classes of this school and 160 students responded to tests of moral judgment, pro-social behavior and anger. Then 40 students were selected who gained lower scores in questionnaires related to dependent variables. Half of these 40 students were randomly assigned to the experimental group and the other half were considered as the control group. The experimental group underwent 10 sessions of the Philosophical Group Training Program (once a week for about 90 minutes) and the control group did not receive any kind of Philosophical Training. At the end of the Training, each group completed the posttest and a follow-up meeting was held after one and a half months. 


\section{Experimental group intervention sessions}

In this study, the Philosophy Training Program was in the form of a search circle or a research community based on Lipman-Sharp Style and the content of some intellectual stories of Volume 3 (Cam, 2013) with its educational instruction and some parts of the Lisa Book (Lipman 2003) and its educational booklet (the School's Great Absent, from Lipman and sharp-volumes 1 and 2) was used in accordance with discussion topics in the class (Table 1). reliability. In this questionnaire, the Alpha was above $70 \%$ which indicates the acceptable reliability of this questionnaire. In the present study, the reliability of the questionnaire was 0.71 for moral judgment which shows the desirable reliability of the questionnaire.

\section{Pro-social Behavior Questionnaire}

The scale of the desirable social trends revised was made by Carlo et al. (2003). The 23-point form of this scale was essentially developed for assessing self-report from 6 types of desired social behaviors

Table 1: The titles of main stories and ideas

\begin{tabular}{|l|l|}
\hline Title of the story & Main idea \\
\hline Fights & Fairness - Violence - Right and wrong \\
\hline Wings & Friendship - Lying or truthfulness - Actions, events and responsibilities \\
\hline Bayes Street & Society - Justice - Issues Of Other People - Courage \\
\hline Robert‘s story & Teasing - Bullying - Duty \\
\hline Play the turn & Lending and borrowing - Retaliation - Rules \\
\hline Three-headed giant & $\begin{array}{l}\text { Defending Beliefs - How can we understand the difference between right } \\
\text { and wrong? Three-headed giant }\end{array}$ \\
\hline Lisa goes shopping & $\begin{array}{l}\text { Why do older people and children disagree - Preferring - Discovering } \\
\text { someone's identity }\end{array}$ \\
\hline
\end{tabular}

\section{Research tools}

Lotf Abadi's Moral Development Questionnaire (2007) is designed in six moral categories as follows: the environmental ethics; ethics of self-care or individual ethics; ethics in family relationships; social ethics; human morality; spiritual or transcendental ethics. Each of the 18 test questions has been assessed with one or more six-grade moral ethics judgments. Aggregate, the sum of the scores related to that dimension in order to measure the score of each dimension. The validity of the questionnaire has been well evaluated and approved using the opinions of Supervisors and Consultants. Also, Cronbach's Alpha Test was used to calculate its among university students. Carlo \& Randall (2002) reported a suitable fitting model using Confirmatory Factor Analysis in university students. In Iran, Kajbaf et al. (2010) investigated the Factor Structure; the validity and credit of this questionnaire (25 items) in the Iranian sample (student) and some changes were applied including the reduction of subscales from 6 to 5. So if you want to run this questionnaire in the student group, use the Iranian standardized version and if your samples are adolescents, this version is more appropriate.

The scale of the desirable social trends revised (PTM-R) is made up of 6 subscales 
of anonymous desired social behaviors (anonymity) (5 questions); friendly type desirable social behaviors (6 questions); desirable emotional social behaviors (5 questions); desirable social behaviors in critical and emergency situations (3 questions); compliant social desirable behaviors (2 questions); collective desirable social behaviors (4). The scoring system used for the questionnaire is a 5-point Likert Scale in which 1, 2, 3, 4, and 5 points are respectively considered for the following options; "Doesn't describes me at all"; "It doesn't describes me somewhat"; "No comments"; "Describes me somewhat"; "Completely describes me".

The minimum and maximum scores that responder achieves on this scale is 25 and 125 respectively. Based on Carlo and Randall's (2003) report, the 6 subscales and Cronbach's Alpha Coefficients of it are as follows: collective desirable social behaviors (4 items, 0.86); anonymous desired social behaviors (anonymity) (5 items, 0.84); desirable social behaviors in critical and emergency situations (3 items, 0.75); desirable emotional social behaviors (5 items, $0.82)$; compliant social desirable behaviors (2 items, 0.75); altruistic desirable social behaviors (6 items, 0.80 ). The reliability of the Pro-social Behavior Questionnaire was 0.67 in the present study which indicates the desirable reliability of the questionnaire.

Eysenck \& Wilson's (1975) Aggression Questionnaire is a tool containing 30 questions that measure and evaluate the levels of aggression in individuals and students. The grading method used is described here: there are + and - symptoms in front of numbers 1 to 30 which are in fact the number of questions. If the symptom of the question is + and the subject also gives a positive answer (yes), then they will receive two points, but if they give a negative answer, there will be no score, in other words, if the subject reply "I don't know the answer" to a question that has a positive sign, he will receive a score. The maximum score in this test is 60 and will be zero in its lowest state. Therefore, it can be said that the score of 30, 25 to 35, shows moderate aggressiveness. Eysen has set the validity of this test himself. So that the test was provided to carry out clinical works and was tested on more than 120,000 women, men, children, adults, normal, nervous and mentally ill individuals, criminals, as well as 2,000 twin couples, and in addition, a large number of adults and children that were used to prepare the original patterns of norms (Ganji 2012). The reliability of the aggression questionnaire in this study was 0.71 , which indicates the reliability of this questionnaire.

\section{Results}

The Kolmogorov-Smirnov Test was used to assess the assumption of variables' scores distribution normality.

Table 2: The assumption of variables' scores distribution normality in the experimental and control groups

\begin{tabular}{|c|c|c|c|}
\hline \multirow[t]{2}{*}{ Groups } & \multirow[t]{2}{*}{$\begin{array}{l}\text { Statistical } \\
\text { indicators } \\
\text { Variables }\end{array}$} & \multicolumn{2}{|c|}{$\begin{array}{l}\text { Kolmogor- } \\
\text { ov-Smirnov } \\
\text { test }\end{array}$} \\
\hline & & $\mathrm{Z}$ & $\mathrm{p}$ \\
\hline \multirow{3}{*}{$\begin{array}{l}\text { Experi- } \\
\text { mental }\end{array}$} & Moral judgment & 0.77 & 0.57 \\
\hline & $\begin{array}{l}\text { Pro-social } \\
\text { behavior }\end{array}$ & 0.86 & 0.44 \\
\hline & Anger control & 0.78 & 0.56 \\
\hline \multirow{3}{*}{ Control } & Moral judgment & 0.68 & 0.73 \\
\hline & $\begin{array}{l}\text { Pro-social } \\
\text { behavior }\end{array}$ & 0.72 & 0.67 \\
\hline & Anger control & 0.90 & 0.39 \\
\hline
\end{tabular}

As shown in Table 2, according to the significance level in the test and control groups of Kolmogorov-Smirnov Test, the assumption of variables' scores distribution normality is confirmed in the studied population. 
Table 3: Homogeneity of Levin Variances in dependent variables of research in pre-test phase

\begin{tabular}{|c|c|c|c|c|}
\hline Variables & $\begin{array}{c}\text { Levine's } \\
\text { statistics }\end{array}$ & $\mathrm{df}$ (between groups) & $\mathrm{df}$ (within the group) & $\mathrm{p}$ \\
\hline Moral judgment & 0.147 & 1 & 38 & 0.70 \\
\hline Pro-social behavior & 0.396 & 1 & 38 & 0.53 \\
\hline Anger control & 1.070 & 1 & 38 & 0.30 \\
\hline
\end{tabular}

The results of Table 3 show the homogeneity of variances, which according to the results of the above table $(\mathrm{p}<0.05)$ and lack of significance in Levine Test, it is permissible to use the covariance analysis test.
As shown in Table 5, statistical tests of multivariate covariance analysis (MANKOVA) in the Philosophy and evidence education program group show that these groups have significant differences with each other at least in one of the dependent variables.

Table 4: Mean and standard deviation of the research variables in the Philosophy and control groups in the pre-test, post-test and follow-up stages

\begin{tabular}{|l|l|c|c|c|c|c|c|}
\hline \multirow{2}{*}{ Variables } & \multirow{2}{*}{ Groups } & \multicolumn{2}{|c|}{ Pre-test } & \multicolumn{2}{c|}{ Post-test } & \multicolumn{2}{c|}{ Follow-up } \\
\cline { 3 - 8 } & & $\mathrm{M}$ & $\mathrm{SD}$ & $\mathrm{M}$ & $\mathrm{SD}$ & $\mathrm{M}$ & $\mathrm{SD}$ \\
\hline $\begin{array}{l}\text { Moral } \\
\text { judgment }\end{array}$ & Experimental & 141.35 & 15.78 & 164.70 & 16.67 & 161.05 & 17.38 \\
\cline { 2 - 8 } & Control & 145.60 & 15.34 & 148.25 & 15.35 & 147.80 & 14.54 \\
\hline $\begin{array}{l}\text { Pro-social } \\
\text { behavior }\end{array}$ & Experimental & 83.95 & 9.13 & 96.35 & 7.72 & 94.50 & 8.15 \\
\cline { 2 - 8 } & Control & 80.80 & 8.83 & 80.35 & 8.69 & 81.50 & 9.55 \\
\hline \multirow{2}{*}{ Follow-up } & Experimental & 20.10 & 5.11 & 28.80 & 5.46 & 28.20 & 4.77 \\
\cline { 2 - 8 } & Control & 23.50 & 5.59 & 24.45 & 6.48 & 24.55 & 5.54 \\
\hline
\end{tabular}

Mean and standard deviation of moral judgment, pro-social behavior and anger control in the Philosophy and control groups in the pre-test, post-test follow-up stages are shown in Table 4.

Table 5: Results of multivariate covariance analysis (MANKOVA) on post-test scores of moral judgments, pro-social behavior and anger control in experimental and control groups

\begin{tabular}{|l|c|c|c|c|c|}
\hline Tests & Value & $\mathrm{F}$ & $\mathrm{df}$ & Error df & $\mathrm{p}$ \\
\hline Pillais Trace & 0.921 & 128.71 & 3 & 33 & 0.001 \\
\hline Wilks Lambda & 0.079 & 128.71 & 3 & 30 & 0.001 \\
\hline Hotelling's Trace & 11.700 & 128.71 & 3 & 33 & 0.001 \\
\hline Roy's Largest Root & 11.700 & 128.71 & 3 & 33 & 0.001 \\
\hline
\end{tabular}


Table 6: Results of single-variable covariance analysis in the text of MANKOVA on post-test scores of moral judgments, pro-social behavior and anger control

\begin{tabular}{|l|l|c|c|c|c|c|c|}
\hline Source & Variables & SS & df & MS & F & $p$ & Effect size \\
\hline \multirow{4}{*}{ Groups } & Moral judgment & 3475.41 & 1 & 3475.41 & 84.23 & 0.001 & 0.706 \\
\cline { 2 - 8 } & Pro-social behavior & 1598.92 & 1 & 1598.92 & 181.86 & 0.001 & 0.839 \\
\cline { 2 - 8 } & Follow-up & 511.65 & 1 & 511.65 & 104.29 & 0.001 & 0.749 \\
\hline
\end{tabular}

As can be seen in Table 6, the findings show that there is a significant difference in the dependent variables (moral judgment, pro-social behavior and anger control) between the intervention teaching Philosophy and control groups. the dependent variables (moral judgment, pro-social behavior and anger control) between the intervention Teaching Philosophy and control groups.

Table 7: Results of multivariate covariance analysis (MANKOVA) scores of moral judgments, prosocial behavior and anger control in experimental and control groups at the follow-up phase

\begin{tabular}{|l|c|c|c|c|c|}
\hline Tests & Value & $\mathrm{F}$ & $\mathrm{df}$ & Error df & $\mathrm{p}$ \\
\hline Pillais Trace & 0.891 & 90.28 & 3 & 33 & 0.001 \\
\hline Wilks Lambda & 0.109 & 90.28 & 3 & 30 & 0.001 \\
\hline Hotelling's Trace & 8.200 & 90.28 & 3 & 33 & 0.001 \\
\hline Roy's Largest Root & 8.200 & 90.28 & 3 & 33 & 0.001 \\
\hline
\end{tabular}

As shown in Table 7, statistical tests of multivariate covariance analysis (MANKOVA) in the Philosophy and Evidence Education Program Goup show that these groups have significant differences with each other at least in one of the dependent variables.

\section{Discussion and Conclusion}

The purpose of this study was to evaluating the effectiveness of the Philosophy Training Program on development of moral judgment, pro-social behavior and anger control among second year High School female students of Ahwaz City.

Table 8: Results of single-variable covariance analysis in the text of MANKOVA on follow-up scores of moral judgments, pro-social behavior and anger control

\begin{tabular}{|l|l|c|c|c|c|c|c|}
\hline Source & Variables & SS & df & MS & F & $p$ & Effect size \\
\hline \multirow{4}{*}{ Groups } & Moral judgment & 2678.32 & 1 & 2678.32 & 70.14 & 0.001 & 0.667 \\
\cline { 2 - 8 } & Pro-social behavior & 1006.78 & 1 & 1006.78 & 129.42 & 0.001 & 0.787 \\
\cline { 2 - 8 } & Follow-up & 358.74 & 1 & 358.74 & 77.38 & 0.001 & 0.689 \\
\hline
\end{tabular}

As can be seen in Table 8, the findings show that there is a significant difference in
Hypothesis 1: The Philosophy Education Program has a positive effect on the 
growth of moral judgment among second year High School female students.

The current research results showed that teaching Philosophy for adolescents is effective on moral judgment development in High School female students and therefore the first hypothesis of the research is confirmed. This finding is consistent with the research results conducted by Jalilian et al. (2017), Azimpour et al. (2015), Tajari (2011), Marashi et al. (2010), Cam (2013) and Mergler et al. (2009). The Teaching Philosophy Program enables students to make connections between various subjects they learn. Therefore, the curriculum will be more meaningful to them. In fact, students' participation in searching for meaning will enhance their cognitive ability and their understanding of reasoning and abstract contents and also increases their moral values.

A Philosophy Education Program for adolescents is one of the most appropriate methods of education that results in educating well-informed and responsible citizens and provides living conditions in a healthy and dynamic society and this is a way to moral development (Marashi et al., 2010). Philosophical thinking requires thinking about thinking. Teenagers learn to examine their thoughts, check the adaptation of their thoughts with evidence, and test their assumptions and examine their relationships with everyday activities. In the method of teaching Philosophy in the form of a searching circle, the language provides the necessary means for thinking and power of moral judgment increases in children through participation and sympathy in these educational sessions (Hayhoe 2014).

Hypothesis 2: The Philosophy Education Program has a positive effect on the pro-social behavior of second year High School female students.

The results of the present study showed that teaching Philosophy for adolescents is effective on the social behavior of second year High School female students and therefore the third hypothesis of the research is confirmed. This finding is consistent with the research results of Ghobadian (2015), Naraghi 1. (2011) \& Naji (2010). In explaining this finding it can be said that Teaching Philosophy is a dialogue-based activity which it's necessary to open the door of dialogue to all members of the community. In other words, it requires a general and common searching approach. When people feel compassion and sympathy for the innocent victims of a catastrophe, they somehow behave much better than they do not having these feelings (Naji 2010).

At same time, Philosophy for children and adolescents has a social purpose. Collaboration and thinking skills that grow and develop in a Philosophy Education Program will improve communication and enhance social responsibility. Lipman believes that realizing the goals and learning a lot of skills is possible through language and creating a research community or study circle which is the best form for children. Individuals can easily express their opinions and do not censor themselves after participating in the philosophical research community (Hedayati 2011).

In another explanation of this hypothesis, it can be said that many skills acquired through this program and the process related to it, in fact, form socialization axes. In the Philosophy Program for children dialogue helps people to correct their thoughts; bring reasons for their beliefs; express vague thinking in a clear way; understand others people's ideas; thereby, raise up their understanding and ability for solving problems of social life and behaviors in the community (Ramezani 2010).

Hypothesis 3: The Teaching Philosophy Program for teenagers has a positive effect on anger control of second year High School female students.

The results of the current study showed that Teaching Philosophy for adolescents is 
effective in controlling anger in second year High School female students and therefore the third hypothesis of the research is confirmed. This finding is consistent with researches of Tajalinia \& Karimi (2014) \& Hedayati (2011). In explaining this finding, it can be said that students' participation in the Philosophy Program leads to the development of those skills that are effective in controlling anger.

Adolescents gradually learn about conversational skills and learn to listen to each other with respect and attention; put their ideas together; criticize them to bring logical reasoning for unconfirmed beliefs; tolerate opposing views if their ideas receive some criticism do not get angry or upset. The lack of tolerance to criticism from other people is the reason for many waves of anger. It also strengthens self-esteem because the higher the self-esteem is, the less the person will expose himself to violence. The Philosophy Education Program also leads to accountability in the individual. A person who is ready to take responsibility for his actions will surely control himself during anger (Tajalinia \& Karimi 2014).

In spite of serious efforts made to properly conduct present research, this research, like other researches on humanitarian issues faced with limitations and difficulties that attempt to resolve them in future studies could confirm the results achieved in this research. Dealing with students is among the limitations of this research and we should be cautious about generalizing the results of this research to other statistical communities. The program encourages children to think and helps them make the right decisions. Students think in dilemmas of life and will choose the right way through this method, so that, new generation's status can be reformed and they can receive help to grow and promote. This program can be considered as part of the students' educational system.

\section{References}

1. AKBARI B, RAHMATI F (2015) The Effectiveness of Cognitive-Behavioral Therapy Based Treatment Game on Reducing Aggression in Preschool Children with Attention Deficit Disorder. Journal of Child Psychological Development. 2: 1-9. In Persian.

2. AKRAMI L, QAMARANI A, YARMOHAMMADIAN A (2015) Effectiveness of Philosophy Education on Ethical Judgment and Self-esteem in Blind Students. Thinking and Child, Institute of Humanities and Cultural Studies. 5. 1-17. In Persian.

3. ATADOKHT A R, BASHARPOUR S, DOLATI H (2016) The role of empathy and Islamic lifestyle in explaining the behavior of the community. Journal of Psychological Studies. 5: 1-11. In Persian.

4. AZIMPOUR A R, ESKANDARI H, EBRAHIMI S (2015) The Effect of Teaching Philosophy on Children on the Ethical Evolution of 5th Primary-School Boy Students in Tehran. Journal of Educational Psychology Studies. 23: 1-18. In Persian.

5. BRAHMAN M, KHODABAKHSHI F (2017) Teaching Philosophy for Children. Journal of Advanced Progress in Behavioral Sciences. 9: 1-15. In Persian.

6. CAM F (2013) Philosophy for Children, Values Education and the Inquiring Society. Journal Educational Philosophy and Theory Incorporating ACCESS, Volume 46, 2014 - Issue 11: Special Issue: Philosophy in Schools.

7. CHADI Y, MARILYN C, DONNA T (2016) The effects of participation in a PFC program on Australian elementary school students. Analytic Teaching \& Philosophical Praxis, 37(1), pp.1-19.

8. GANJI H (2012) Personality Evaluation, Second Edition, Publication of Savalan. Tehran. Iran.

9. GHOBADIAN M (2015) Effect of Philosophy Education Program on Children's Skills 
on Elementary School Students. Educational Research. 30:1-12. In Persian.

10. GRAVAND P, MANASHI G R (2015) The Effectiveness of Exercise Training and Social Skills Training on Communication Aggression, Revealed and Community-Friendly Behavior of Aggressive Adolescents in Khorramabad City. Journal of Disability Studies 5:190-199 In Persian.

11. HAYHOE S (2014) Does Philosophy Disable? The Epistemological Model OF Disability, and The Influence of The Process of Knowledge Construction On People With Impairments', School of Childhood Studies and Education Sciences, Canterbury Christ Church University/Centre for the Philosophy of Natural and Social Science, London School of Economics and Political Science, UK.

12. HEDAYATI M (2011) Philosophy for Children and Control of Aggression, Thinking and Child, Institute for Human Sciences and Cultural Studies. 2: 109-134. In Persian.

13. JALILIAN S, AZIMPOUR E, JALILIAN F (2017) The Effectiveness of the Philosophy Education Program for Kids on the Development of Problem Solving Ability and Ethical Judgment in Students. Educational Research. 32: 1-22. In Persian.

14. JUUSO H (2007) 'Child, Philosophy and Education, Discussing the Intellectual Sources of Philosophy for Children', Department OF Educational Sciences and Teacher Education.

15. KAJBAF MB, SAJJADIAN I, NOORI A (2010) Investigating factor structure, validity and validity of the scale of desirable social tendencies among students. Applied Sociology. 21: 101-118. In Persian.

16. LENG L (2015) The role of philosophical inquiry in helping High School students engage in Learning and seek meaning in lives. Doctor of Philosophy in educational psychology.

17. LIPMAN M (2003) Thinking in Education, 2nd, Cambridge and New York: Lockwood
PL, Seara-Cardoso A, \& Viding E (2014) Emotion Regulation Moderates the Association between Empathy and Prosocial Behavior. 9(5), 12-32.

18. LOTFABADI H (2007) National and global citizenship education students with consolidated identity and value system. Quarterly Scientific Educational Innovations, 17, 1144. (In Persian).

19. MAHDAVI M, ZAREI S (2011) Factors Affecting Adolescents' Proportion to Ethical Values in Secondary School Students Hamedan Province. Journal of Sociological Studies, 1:1-21.In Persian.

20. MARASHI M, SAFAEI-MOGHADDAM M, KHAZAMI P (2010) The Effect of Implementation of Philosophy Education Program for Children by Research Methodology on the Growth of Ethical Judgment in Primary School Students in Ahwaz City. Thinking and Child, Institute of Humanities and Cultural Studies. 1: 83-102. (In Persian).

21. MAROOFI Y, MOHAMMADNIA I (2013) Bilingualism and its relationship with critical thinking skills. Journal of Educational Innovation. 12: 45-60. (In Persian).

22. MARTIN-RAUGH M P, KELL H J, MOTOWIDLO S J (2016) Prosocial knowledge mediates effects of agreeableness and emotional intelligence on prosocial behavior. Personality and Individual Differences, 90, 41-49.

23. MASI D D, SANTI M (2015) Learning democratic thinking: a curriculum to Philosophy for children as citizens. Journal of Curriculum Studies, 48, 136-150.

24. MERGLER A, CURTIS E, SPOONER-LANE R (2009) Teacher education embrace Philosophy: reflections on a new way of looking at preparing pre-service teachers. Journal of teacher education. 34, (5) 33-21.

25. NAJI S (2010) Philosophical Conduct for Children and Young Adults. Institute of Humanities and Cultural Studies. 1. (In Persian). 
26. NARAGHI M, GHOBADIAN M, NADERI E, SHARIATMADARI A (2011) An Effective Social Research Community on Child Development. Thinking and Child, Institute of Humanities and Cultural Studies. 2: 1-22. In Persian.

27. RAMEZANI M (2010) A Study of Philosophy Curriculum for Children in Respect of Different Dimensions of Philosophical Mind. Thinking and Child, Institute of Humanities and Cultural Studies. 1: 1-16. In Persian.

28. SANTROCK J W (2014) Adolescence, Fifteenth Edition. Published by McGraw-Hill Education, 2 Penn Plaza, New York, NY 10121. Printed in the United States of America.
29. TAJALINIA A, KARIMI R (2014) The effect of the implementation of the Philosophy program for children on decreasing and suppressing the anger of first grade High School students in Tehran. Thinking and Child, Institute of Humanities and Cultural Studies. 5: 39-63. (In Persian).

30. TAJARI E (2011) The effect of the program of teaching Philosophy on adolescents on the development of their moral judgment using Golestan stories. Master's thesis on history and Philosophy of education. Al-Zahra University. In Persian.

31. UHLMANN E L, DAVID A PIZARRO, DIERMEIER D (2015) A Person-Centered Approach to Moral Judgment. Perspectives on Psychological Science, 10(1) $72-81$. 